\section{Adolescent health}

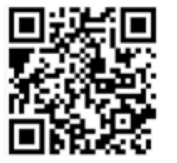

The period of adolescence is associated with complex psychological, physical and cognitive changes as children transition to adulthood. In more recent times this transition has taken on added complexities, particularly in developing countries undergoing social and political changes, in an era of increasing globalisation and access to information through new technologies. While adolescents comprise about $25 \%$ of the global population, they constitute up to $40 \%$ of the population in sub-Saharan Africa, creating what is also referred to as the 'youth bulge' in the population pyramid. This demographic shift in sub-Saharan Africa is also associated with poorer health outcomes in adolescents as a result of a convergence of communicable and non-communicable diseases. Notably, the gender gaps in infant and childhood survival are being reversed, with secondary sexual development resulting in increasing vulnerability of young women, which perpetuates vicious cycles of intergenerational poverty, low levels of schooling, and ill health that undermine social and economic transformation in these settings.

Given the importance of this topic, the $S A M J$ has dedicated two special CME issues to it. In this first part, the focus is on sexual and reproductive health, including HIV and AIDS. The contribution by Baxter and Moodley ${ }^{[1]}$ highlights the negative outcomes of teenage pregnancies and the impact on maternal mortality rates and indirect impact on infant mortality rates and overall increase in disease burden of HIV and tuberculosis. The article by Dellar et al. ${ }^{[2]}$ links and contextualises HIV service provision with other sexual reproductive health needs of young women and provides specific guidance to clinicians on opportunities and specific action that clinicians can take in providing health services to adolescents. While there have been huge reductions in vertical transmission of HIV and a decline in AIDS-related deaths in infants with early antiretroviral (ARV) treatment initiation, these infants and children are now transitioning to adolescence. In addition to the usual challenges faced by adolescents, HIV-infected children often have to face for the first time that they have AIDS and need to be on lifelong ARV treatment. The articles by Naidoo et al. ${ }^{[3]}$ and Dawood ${ }^{[4]}$ underscore some of the challenges in treating adolescent AIDS patients and issues that need to be considered, such as drug choices, treatment adherence, disclosure of HIV status, fear of stigma and discrimination and its implications with regard to secondary sexual development, and risks associated with horizontal transmission of HIV. Waning immunity from childhood immunisation and the development of new vaccines requiring delivery during adolescence introduce new challenges relating to vaccine delivery beyond childhood. The article by Tathiah et al. ${ }^{[5]}$ shares experiences in the introduction of the human papillomavirus vaccine, which provides a strong foundation for the introduction of vaccines that target adolescents but are still being developed.

\section{Quarraisha Abdool Karim}

Guest editor

quarraisha.abdoolkarim@caprisa.org

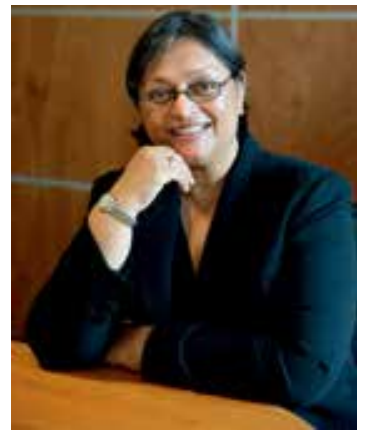

. Baxter C, Moodley D. Improving adolescent maternal health. S Afr Med J 2015;105(11):948-952. [http://dx.doi.org/10.7196/SAM].2015.v105i11.10126]

2. Dellar R, Waxman A, Abdool Karim Q. Understanding and responding to HIV risk in young South African women: Clinical perspectives. S Afr Med J 2015;105(11):952. [http://dx.doi.org/10.7196/ SAMJ.2015.v105i11.10099]

3. Naidoo K, Munsami A, Archary M. Adolescent antiretroviral management: Understanding the complexity of non-adherence. S Afr Med 2015;105(11):953. [http://dx.doi.org/10.7196/SAMJ.2015.v105il1.10150] Dawood H. Adolescent HIV treatment issues in South Africa. S Afr Med J 2015;105(11):953. [http:// dx.doi.org/10.7196/SAMJ.2015.v105i11.10130]

5. Tathiah H, Naidoo M, Moodley I. Human papillomavirus (HPV) vaccination of adolescents in the South African private health sector: Lessons from the HPV demonstration project in KwaZulu-Natal. S Afr Med J 2015;105(11):954. [http://dx.doi.org/10.7196/SAMJ.2015.v105i11.10135]

S Afr Med J 2015;105(11):948. DOI:10.7196/SAMJ.2015.v105i11.10195 